\title{
USO DA ANÁLISE DE DECISÃO MULTICRITÉRIO EM PROCESSOS LICITATÓRIOS PÚBLICOS: UM ESTUDO DE CASO
}

\section{USE OF MULTI-CRITERIA DECISION ANALYSIS IN PUBLIC BIDDING PROCESSES: A CASE STUDY}

\author{
André Andrade Longaray* E-mail: longaray@yahoo.com.br \\ Guilherme Brandelli Bucco** E-mail: guilherme.brandelli@yahoo.com.br \\ * Universidade Federal do Rio Grande (FURG), Rio Grande, RS \\ *Universidade Federal do Rio Grande do Sul (UFRGS), Porto Alegre, RS
}

\begin{abstract}
Resumo: As Instituições Federais de Ensino Superior (IFES) ocupam importante papel no desenvolvimento social e científico brasileiro. Com seu foco principal voltado às atividades de ensino, pesquisa e extensão, as IFES contam com a assessoria de fundações de apoio para a gestão dos recursos financeiros, humanos e materiais. Caracterizadas como órgãos públicos, as fundações de apoio são regidas pela Lei $n^{0}$ 8.666/93 no que tange às contratações e aquisições de bens e serviços. Diante desse cenário, o objetivo do presente trabalho consiste no desenvolvimento de um modelo para auxiliar os gestores de uma fundação de apoio na seleção de fornecedores para processos licitatórios do tipo carta-convite. Para tanto, foi realizado um estudo de caso em uma das 55 fundações de apoio das universidades federais brasileiras. $O$ instrumento de intervenção utilizado foi a Análise Hierárquica de Processos (AHP). Em um primeiro momento, foi estabelecida a estrutura hierárquica dos critérios para o problema. Em seguida, feita a comparação pareada entre os critérios de mesmo nível. Após, foi verificada a análise de consistência das matrizes de comparação. Por fim, foram obtidas as prioridades relativas de cada critério e procedida a construção da função-objetivo do modelo. O modelo foi testado por meio da avaliação do desempenho de três propensos fornecedores de material de informática e seu resultado foi legitimado pelos decisores, os quais consideraram o instrumento válido como ferramenta de auxílio nas decisões na seleção de fornecedores para a fundação.
\end{abstract}

Palavras-chave: Abordagens Multicritério. Fundações de Apoio às IFES. Serviço Público. Análise Hierárquica de Processos.

Abstract: Institutions of Higher Education in Brazil (IFES) play an important role in the country's social and scientific development. Focused mainly on teaching, research and extension activities, the IFES are backed by support foundations aimed to the management of financial, human and material resources. Characterized as public bodies, the support foundations are governed by Law no 8.666/93 in what concerns the procurement of goods and services. Therefore, the present study is aimed to develop a model to assist the managers of such foundations in the selection of suppliers to participate in bidding processes that use invitation for bids. Therefore, we conducted a case study in one of the 55 foundations that support Brazilian federal universities. The intervention tool used was the Analytic Hierarchy Process (AHP). Firstly, we established the hierarchy of criteria for problem-solving. Then, a paired comparison was made between criteria for the same level. Subsequently, the consistency analysis of comparison matrices was verified. Finally, the relative priorities of each criterion were obtained and the objective function of the model was constructed. The model was tested through the assessment of the performance of three potential suppliers of IT equipment, and the result was legitimized by decision makers who found the instrument a valid tool to aid in making decisions on supplier selection for the foundation. 
Keywords: Multi-criteria Approaches. IFES Support Foundations. Public Service. Analytic Hierarchy Process.

\section{INTRODUÇÃO}

As Instituições Federais de Ensino Superior (IFES) são instituições criadas ou incorporadas pela União, com atividades relacionadas ao ensino, pesquisa e extensão.

No que tange ao aspecto de responsabilidade e função social, o papel das universidades é amplo. Integram esse escopo as funções de formação de profissionais, de desenvolvimento de pesquisa científica, de incentivo à cultura e à arte, de fornecimento de análises sociais, de contribuição para o desenvolvimento econômico, social e tecnológico, e de assistência social.

Atender às demandas da sociedade por uma participação mais ativa nestas $e$ em outras funções é uma tarefa árdua, especialmente em se tratando de um país de dimensões continentais, que passa atualmente por profundas mudanças.

Uma das condicionantes para que as universidades continuem tendo papel relevante no desenvolvimento social e da ciência, oferecendo ensino e pesquisa com eficiência e qualidade, é a boa gestão dos seus recursos financeiros, humanos e materiais. Diante deste imperativo, as atividades administrativas têm importância fundamental, e para auxiliar as universidades nessa tarefa foram criadas as fundações de apoio às IFES.

As fundações de apoio das universidades públicas, dentre outras atribuições, são responsáveis pelo gerenciamento de todas as fases dos processos de compras das IFES. Das fases, a etapa de seleção e cadastro de fornecedores se reveste de grande relevância.

Inserido neste contexto, o presente trabalho apresenta a utilização de um método multicritério de apoio à decisão para auxiliar os gestores do setor de compras da fundação de apoio de uma das 55 universidades federais brasileiras na seleção de fornecedores aptos a participarem dos processos licitatórios na modalidade carta-convite.

Para tanto, o artigo está organizado em cinco seções. Após esta introdução, a seção 2 apresenta um panorama sobre as fundações de apoio às IFES e seu processo de compras. A seção 3 trata da Análise Hierárquica de Processos (AHP), abordagem multicritério adotada no trabalho. A seção 4 delineia os aspectos 
metodológicos da pesquisa. A seção 5 descreve a utilização do AHP no desenvolvimento de um modelo para a seleção dos fornecedores. Por fim, a seção 6 estabelece as considerações finais a respeito da pesquisa, seguida das referências bibliográficas consultadas.

\section{AS FUNDAÇÕES DE APOIO E O PROCESSO DE COMPRAS DAS UNIVERSIDADES PÚBLICAS FEDERAIS}

As fundações de apoio às IFES são organizações da iniciativa privada sem fins lucrativos. Caracterizam-se, portanto, como organizações pertencentes ao chamado terceiro setor. Por conta disso, cabe fazer uma caracterização deste setor, no intuito de contextualizar o presente trabalho.

Dá-se o nome de terceiro setor a uma diversidade de organizações que cumprem algum papel social coletivo, em sua maioria de utilidade pública, e que diferem do primeiro setor (o Mercado) e do segundo setor (o Estado). Assim, o termo terceiro setor

\footnotetext{
sugere elementos amplamente relevantes. Expressa uma alternativa para as desvantagens tanto do mercado, associadas à maximização do lucro, quanto do governo, com sua burocracia inoperante. Combina a flexibilidade e a eficiência do mercado com a equidade e a previsibilidade da burocracia pública. (COELHO, 2002, p. 58).
}

A forma de atuação das entidades do terceiro setor pode se manifestar em diversos tipos. Há as organizações assistenciais, desenvolvimentistas, ambientalistas, os hospitais, igrejas, fundações, entre outros. Contudo, o que mais contribui para a caracterização, para a definição do perfil de uma organização do terceiro setor são os clientes a que ela presta serviço. As necessidades destes clientes dão forma à sua atuação e organização interna.

Ainda que haja uma grande diversidade de finalidades, o que todas têm em comum é a ausência de fins lucrativos, sendo, consequentemente, regidas por uma legislação específica. Possuem, dentre outras características especiais, isenções fiscais. Isso funciona, de acordo com Coelho (2002), como uma espécie de "premiação" por atuarem onde o governo deveria atuar.

As origens dos recursos para a manutenção das suas atividades serão classificadas, para fins deste trabalho, em públicas e privadas. Quando se trata de Revista Produção Online, Florianópolis, SC, v.14, n. 1, p. 219-241, jan./mar. 2014. 
repasses de origem pública, o Estado utiliza mecanismos para controle do seu uso. Neste caso, tais organizações devem prestar contas das suas atividades.

As fundações de apoio às IFES, que formam o contexto de estudo deste trabalho, são instituídas com o objetivo de atender às demandas que as universidades não conseguem suprir.

Nesse sentido, as universidades possuem alguns de seus projetos financiados por recursos públicos, de forma que devem atender à legislação pertinente. Assim, no que diz respeito às contratações e aquisições, devem seguir a Lei no 8.666/93 (BRASIL, 1993), que institui a licitação como regra para as contratações.

Tal lei institui as modalidades de licitações e todas as regras a serem seguidas nos processos de compras e contratações. Dentre elas, a carta-convite (art. 22, § $3^{\circ}$ da referida lei), que deve ser enviada a no mínimo três fornecedores escolhidos pela unidade administrativa. Há ainda os casos elencados no art. 24 da mesma lei, em que a licitação é dispensável.

A administração das fundações de apoio encontra-se, portanto, diante do imperativo de ter que decidir entre quais fornecedores convidar a participar dos processos de aquisição. É sabido que há grande variação na qualidade dos produtos e serviços prestados, de forma que uma pré-seleção rigorosa, segundo critérios racionais, deve contribuir para contratações que atendam às demandas da universidade de maneira mais satisfatória.

Diante desse cenário, o problema da seleção de fornecedores (Suppliers Selection Problem) tem sido vastamente investigado na comunidade científica da pesquisa operacional (DE BOER et al., 2001; CHEN, 2011). Da diversidade de possibilidades para resolução do mesmo, os métodos multicritério vêm sendo empregados com êxito (ALMEIDA, 2007; HO, 2008; SALOMON et al., 2009; FERREIRA e SANTI, 2012; GOMES et al., 2013).

A revisão da bibliografia sobre abordagens multicritério para a avaliação e seleção de fornecedores proposta por Ho et al. (2010) ressalta que preço ou custo não são os critérios mais amplamente adotados, mas, ao contrário, estão no terceiro grupo - precedido por qualidade e entrega. Isto demonstra, segundo os autores, como os tradicionais métodos monocritério, baseados em menor custo, não são robustos o suficiente para a gestão de suprimentos contemporânea. 
Dentre os critérios para a seleção de fornecedores, pode-se citar: prazo de entrega, cumprimento do prazo de entrega, qualidade do produto/serviço, assistência técnica, entre outros. É possível avaliar-se um dado fornecedor, segundo estes critérios, pesquisando-se o seu histórico em processos de compras prévios.

É neste panorama que se insere o objetivo do presente trabalho: desenvolver um instrumento de seleção de fornecedores de uma fundação de apoio a uma universidade federal, por meio da utilização do método de Análise Hierárquica de Processos (AHP). A questão de pesquisa norteadora do trabalho é: como os gestores de fundações de apoio às IFES devem proceder para a seleção de fornecedores?

\section{MÉTODO AHP}

Muitos problemas concretos se prestam para serem modelados por métodos monocritério e resolvidos por meio de técnicas adequadas, tais como a programação linear. Outros, porém, devido à sua complexidade inerente, necessitam de ponderações sobre mais de um aspecto (LONGARAY e ENSSLIN, 2013). A utilização de um método multicritério pode contribuir para a diminuição do subjetivismo, tendenciosidade e arbitrariedade do processo (PAULA e MELLO, 2013).

Encontra-se na literatura uma variedade de métodos multicritério (LONGARAY et al., 2010). A maneira como cada um deles trabalha as alternativas é que os diferencia. Salomon (2002) cita os métodos da família ELECTRE (Elimination and Choice Translating Reality), que fornecem ordenação das alternativas, e outros, que fornecem, também, medidas de desempenho, como o AHP (Analytic Hierarchy Process), ANP (Analytic Network Process), FDA (Fuzzy Decision Approach), MACBETH (Measuring Attractiveness by a Categorical Based Evaluation Technique) e TOPSIS (Technique for Order Preference by Similarity to Ideal Solution).

A seleção de fornecedores (Suppliers Selection Problem), que é o problema analisado neste trabalho, é um exemplo de decisão complexa, que exige a consideração de mais de um critério. Nesta pesquisa, optou-se pelo uso do AHP por conta da sua ampla aplicabilidade, robustez e flexibilidade (HO, 2008). 
Proposto por Thomas Saaty (1991), o AHP tem sido utilizado com sucesso em uma diversidade de problemas complexos, tais como o problema da priorização do embarque marítimo (BANDEIRA et al., 2010), da gestão de resíduos sólidos domiciliares (MARCHEZETTI et al., 2011), da avaliação dos serviços oferecidos por operadoras de planos de saúde (WOLLMANN et al., 2012), da avaliação de prioridades de competição em cadeias de suprimento (SILVA et al., 2012), da análise estratégica (DIAS et al., 2011), dentre outros.

No que tange ao problema da seleção de fornecedores, o AHP possui uma variedade de aplicações descritas na bibliografia (SALOMON, 2002; LIU e HAI, 2005; RIBEIRO et al., 2012).

Deve-se, contudo, tomar em consideração a singularidade de cada situação problemática em que se dá o uso do método (LONGARAY, 2007). Conforme Subramanian e Ramanathan (2012), o emprego do AHP é orientado a estudos de caso e leva em conta opiniões subjetivas dos atores daquele cenário em particular, personalizando o processo de tomada de decisão.

Embora as áreas de logística e cadeia de suprimentos tenham representado a maioria de aplicações do AHP no levantamento procedido em sua pesquisa, Subramanian e Ramanathan (2012) assinalam que não foi possível encontrar significativa quantidade de utilização desse método multicritério nos setores de serviços, tais como hospitais, bancos, hotéis e no setor que constitui o contexto do presente trabalho: educação.

A esse respeito, Ensslin, Ensslin, Rocha, Marafon e Medaglia (2013), ressaltam a limitação de pesquisa científica sobre o uso do AHP em problemas cuja ênfase seja a da administração pública.

O presente estudo visa contribuir, por meio do uso do método AHP, em um problema de um contexto específico, do segmento das fundações de apoio, no âmbito das IFES. A presente pesquisa pretende, ainda, estender a gama de possibilidades de critérios utilizados para a solução do problema da seleção de fornecedores em processos licitatórios públicos (ISHIZAKA, 2012).

Sob uma perspectiva metodológica, o AHP deve ser entendido mais como um facilitador, um processo de estruturação de pensamento, do que como um algoritmo que resolve problemas. Dois de seus principais benefícios são: a imposição de disciplina e consistência no processo de pensamento; e o questionamento de 
perguntas que eventualmente são esquecidas em processos de tomada de decisão (COLIN, 2007).

O AHP é modelado na forma de uma estrutura hierárquica descendente, de um objetivo geral para critérios, subcritérios e alternativas, em níveis sucessivos (SAATY, 1991). Em outras palavras, o objetivo principal é posto no primeiro nível, que é decomposto em objetivos secundários, e estes são sucedidos pelas alternativas de decisão, numa quantidade de níveis e critérios que represente o problema da forma mais completa possível, sem que, no entanto, implique na perda de sensibilidade a mudanças nos elementos do modelo.

A partir desta estrutura hierárquica, sucedem as seguintes etapas: julgamento dos critérios, avaliação da consistência dos julgamentos e síntese das prioridades.

O julgamento dos critérios é feito por meio da comparação par a par, utilizando-se uma escala desenvolvida por Saaty (1990). Tal escala é apresentada no Quadro 1.

Quadro 1. Escala fundamental de Saaty
\begin{tabular}{|l|l|}
\hline $\begin{array}{c}\text { Intensidade de importância } \\
\text { numa escala absoluta }\end{array}$ & \\
\hline 1 & Igual importância \\
\hline 3 & Moderada importância de um sobre o outro \\
\hline 5 & Importância essencial ou forte \\
\hline 7 & Importância muito forte \\
\hline 9 & Importância extrema \\
\hline $2,4,6,8$ & $\begin{array}{l}\text { Valores intermediários entre dois julgamentos } \\
\text { adjacentes }\end{array}$ \\
\hline Recíprocos & $\begin{array}{l}\text { Se a atividade } i \text { tem um dos números acima quando } \\
\text { comparada com a atividade } j \text {, então a atividade } j \text { tem o } \\
\text { valor recíproco quando comparada com } i\end{array}$ \\
\hline
\end{tabular}

Fonte: Adaptado de Saaty (1990)

O resultado da comparação par a par é organizado na forma de uma matriz de comparação, como ilustrado na Figura 1.

Figura 1 - Matriz recíproca genérica

$$
A=\left[\begin{array}{cccc}
1 & a_{12} & \cdots & a_{1 n} \\
1 / a_{12} & 1 & \cdots & a_{2 n} \\
\vdots & \vdots & \cdots & \vdots \\
1 / a_{1 n} & 1 / a_{2 n} & \cdots & 1
\end{array}\right]
$$

Fonte: Ramos Filho, Atmanczuk e Marçal (2010) 
Em seguida, as matrizes de comparação são manipuladas para a obtenção das prioridades relativas de cada um dos critérios. As prioridades deverão ser números entre 0 e 1, e sua soma deve ser 1 (COLIN, 2007). Repete-se esse processo para cada conjunto de critérios, em todos os níveis da estrutura.

No passo seguinte, avalia-se a consistência dos julgamentos efetuados pelo decisor. A condição necessária e suficiente para que as matrizes de julgamento sejam consistentes é que o seu principal autovalor $\lambda_{\max }$ seja igual a $n$, onde $n$ é a ordem da matriz (SAATY, 1990). Quando uma dada matriz é inconsistente, caso em que $\lambda_{\max }>n$, essa inconsistência pode ser calculada pela desigualdade $\lambda_{\max }-n$, e um quociente de consistência ( $\mathrm{CR}$ - Consistency Ratio) pode, então, ser calculado. Saaty (1990) propôs a Eq. (1) para o cálculo deste quociente.

$C R=\frac{\left(\lambda_{\max }-n\right)}{(n-1) R I}$

Os cálculos do autovalor $\lambda_{\max }$ da matriz de comparações e dos autovetores normalizados associados a este trabalho foram feitos de acordo com o procedimento descrito por Saaty (1991).

O índice RI (Random Consistency Index) é obtido pela média de um grande número de matrizes recíprocas de mesma ordem, cujas entradas são aleatórias. Saaty (1991) recomenda que o quociente CR seja igual ou inferior a 0,2, de forma que quocientes maiores demandam uma revisão dos julgamentos. A Tabela 1 apresenta valores de RI para matrizes de ordem 3 a 10.

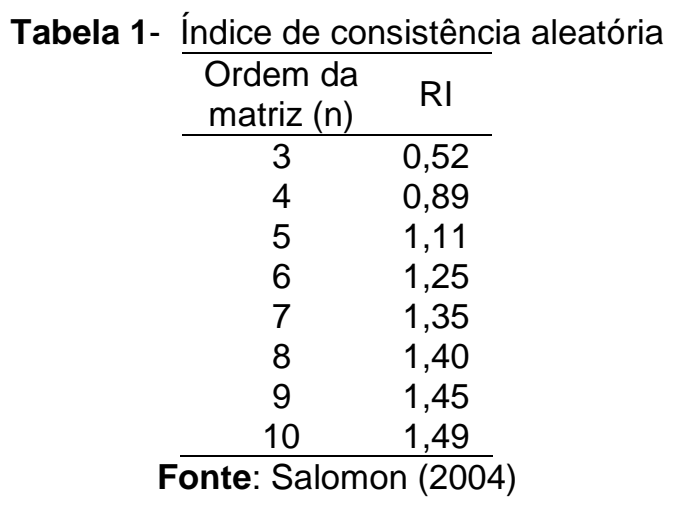

Revista Produção Online, Florianópolis, SC, v.14, n. 1, p. 219-241, jan./mar. 2014. 
Por fim, agregam-se as prioridades relativas encontradas, de modo que se obtenha a melhor decisão para o problema formulado.

\section{PROCEDIMENTOS METODOLÓGICOS}

Esta seção explicita o delineamento metodológico da pesquisa. Classifica o trabalho quanto à finalidade, natureza, fonte de coleta de dados, lógica de pesquisa, abordagem metodológica e o instrumento de intervenção empregado (GIL, 2002; MIGUEL, 2010).

No que tange à sua finalidade, a pesquisa enquadra-se como um estudo exploratório. De acordo com Gil (2002), estudos exploratórios têm o objetivo principal de desenvolver ideias e conduzir a procedimentos relativamente sistemáticos para a obtenção de observações empíricas, bem como possibilitar a identificação das relações entre os fenômenos estudados. Tal perspectiva se alinha com os objetivos desta pesquisa.

O objetivo geral consiste em construir um modelo personalizado para auxiliar os gestores do setor de compras de uma fundação de apoio de determinada IFES na seleção de fornecedores para a modalidade de licitação de carta-convite. Os objetivos específicos para a consecução desta pesquisa são: a identificação dos critérios e subcritérios do modelo; o estabelecimento da hierarquia entre os critérios; a determinação das preferências relativas entre cada elemento de decisão; a análise de consistência das matrizes de comparação, a normalização das matrizes e elaboração da função-objetivo; e a avaliação das alternativas de decisão.

Quanto à sua natureza, esta pesquisa se caracteriza como um estudo de caso (YIN, 2005). Este foi realizado em uma das 55 fundações de apoio às IFES brasileiras. Localizada no Estado do Rio Grande do Sul, ela atende a uma universidade com cerca de 2.000 servidores e aproximadamente 16.000 alunos de graduação e pós-graduação. É responsável pela gestão administrativo-financeira de mais de duas centenas de projetos institucionais de pesquisa, ensino e extensão, aos quais deve assessorar realizando contratações de recursos humanos e serviços terceirizados, compra de materiais permanentes e materiais de consumo.

Como fonte de coleta de dados, o trabalho emprega entrevistas, análise documental e pesquisa bibliográfica (MIGUEL, 2010). Foram realizadas entrevistas Revista Produção Online, Florianópolis, SC, v.14, n. 1, p. 219-241, jan./mar. 2014. 
não estruturadas para a obtenção dos dados primários e o levantamento de documentos e pesquisa bibliográfica como fonte de dados secundários.

A lógica de pesquisa adotada é mista. Ela é indutiva na fase de estruturação do modelo, onde não se parte de princípios, mas sim dos fatos resultantes de observações e da inserção na realidade. Assume a perspectiva dedutiva nas fases de realização dos julgamentos e de síntese das prioridades, pois a partir do modelo construído estabelecem-se conclusões particulares (GIL, 2002).

A abordagem metodológica do trabalho é quali-quantitativa. Gil (2002) defende a ideia de combinar métodos quantitativos e qualitativos, com o intuito de proporcionar uma base contextual mais rica para interpretação e validação dos resultados de uma pesquisa. Sob essa ótica, o presente estudo é quantitativo nas etapas de realização de julgamentos e de síntese de prioridades e qualitativo na etapa de estruturação.

O instrumento de intervenção selecionado para apoiar os gestores do setor de compras da fundação na seleção de fornecedores é o AHP. A escolha por este método multicritério se deve à sua capacidade de proporcionar condições de identificação, operacionalização e mensuração dos critérios e seus níveis (subcritérios) em uma forma robusta e estruturada.

\section{DESENVOLVIMENTO DO MODELO}

O método AHP é aplicado em três etapas: estruturação do modelo, realização dos julgamentos e síntese das prioridades. Tais etapas são apresentadas a seguir.

\subsection{Estruturação do modelo}

Conforme descrito anteriormente, a unidade de análise desta pesquisa é uma fundação de apoio a uma IFES, onde se realizam compras e contratações dos mais diversos produtos e serviços, todas com o objetivo de apoiar as atividades da universidade à qual se vincula.

A função compras ocupa um papel muito importante, contribuindo para o melhor aproveitamento dos recursos escassos nas organizações. Por meio da correta seleção e qualificação de fornecedores, avaliação do desempenho dos 
mesmos, estabelecimento dos termos de vendas, entre outros, é possível reduzir consideravelmente os custos das operações.

O problema abordado neste estudo é a seleção de fornecedores, para os quais serão remetidas cartas-convite para participação de licitações e processos de dispensa de licitação. Ainda que a participação em tais eventos seja pública e qualquer pessoa interessada e habilitada possa fazê-lo, fica a cargo da administração enviar convites a no mínimo três fornecedores. E cabe aos administradores do setor de compras fazer tal seleção.

Atualmente, a decisão quanto ao envio dos convites não é tomada segundo critérios formalmente discutidos e estabelecidos, mas sim baseia-se na experiência dos compradores com os fornecedores que participam dos processos de compras com mais frequência. Propõe-se, assim, um método racional e estruturado para esta decisão, por meio da construção de um modelo utilizando-se o AHP.

Para tanto, inicialmente, por meio das entrevistas, obteve-se informações para elencar os critérios relevantes à decisão. Tais critérios foram estruturados em uma hierarquia (LONGARAY et al., 2013), apresentada na Figura 2.

Figura 2 - Hierarquia de critérios para a seleção de fornecedores

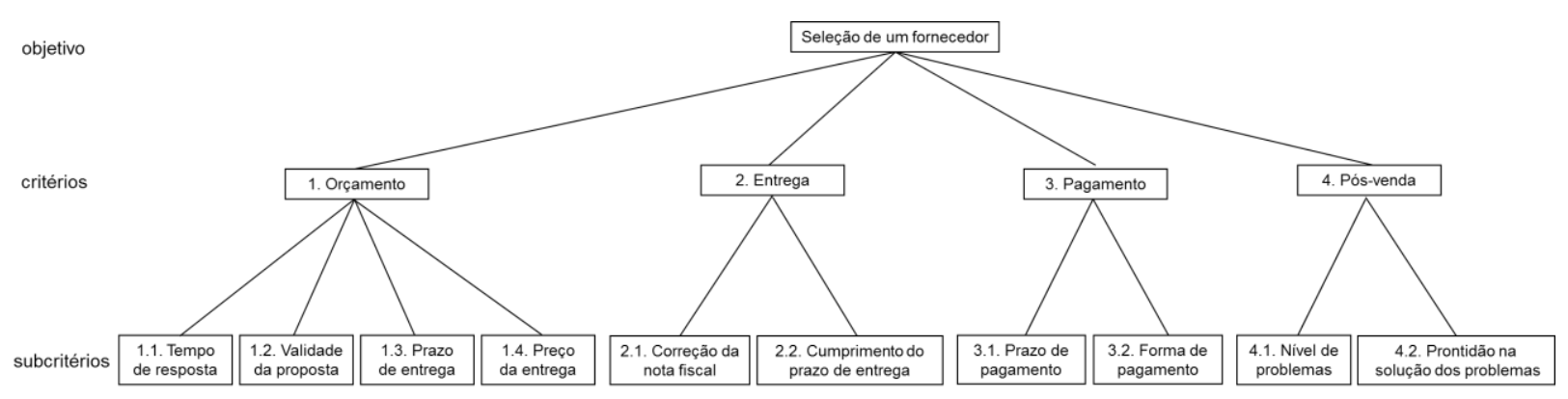

Observa-se, na Figura 2, que no Nível 1 situa-se o objetivo do modelo. Todos os critérios do nível abaixo (Nível 2) são vinculados a ele, visando contribuir, cada qual com a sua prioridade relativa, para a sua consecução.

No Nível 2 foram identificados os critérios "Orçamento", "Entrega", "Pagamento" e "Pós-venda", os quais correspondem às etapas sucessivas de um processo de compras. Ao levantamento dos orçamentos (em número mínimo de 
três) e fechamento da compra, seguem-se a entrega do material comprado, o pagamento devido e uma avaliação dos produtos/serviços.

Finalmente, encontram-se no terceiro nível os critérios quantificáveis, que servem de referência para avaliar diretamente as alternativas de decisão.

Com relação ao critério "Orçamento", foram determinados como mais relevantes para a sua descrição os critérios "Tempo de resposta" - à solicitação de orçamento -, "Validade da proposta", "Prazo de entrega" - do(s) produto(s) - e "Preço da entrega" - o qual serviu para avaliar se: o fornecedor iria se encarregar da entrega do(s) produto(s) sem cobrar por isso; iria entregar os produtos cobrando pela entrega; ou não se encarregaria da entrega, o que, para o setor de compras da fundação, traduz-se em novos contatos com transportadoras, tomando tempo que poderia ser usado em outras tarefas.

Para avaliar-se o critério "Entrega" foram adotados os critérios "Correção da nota fiscal", a qual, se houvesse erros, necessitaria de contatos e tempo despendidos para sua devida correção, sem contar o atraso no pagamento, e "Cumprimento do prazo de entrega", critério bastante relevante, pois um atraso na entrega pode acarretar atrasos na execução dos projetos administrados pela organização.

Em seguida, selecionou-se, com vistas a avaliar o critério "Pagamento", o "Prazo de pagamento", contado da entrega do documento fiscal, e a "Forma de pagamento". Tendo em vista que os projetos administrados pela fundação têm conta corrente no Banco do Brasil, a transferência por esta via, ou ainda um pagamento através de boleto de cobrança, é mais fácil e sem custo, ao passo que os pagamentos por cheque (aplicáveis a outros bancos) ou transferência eletrônica disponível (TED) trazem custos.

Por fim, o critério "Pós-venda" foi avaliado segundo o "Nível de problemas" que o(s) material(is) apresentaram e a "Prontidão na solução dos problemas". Nenhum fornecedor está livre de comercializar produtos que apresentem defeitos do fabricante. Assim, a forma e o tempo que toma para resolver tais problemas é um critério bastante relevante.

O modelo apresentado na Figura 2, estruturado de acordo com o método $\mathrm{AHP}$, apresenta o conjunto de critérios que serão utilizados para o apoio à tomada 
de decisão, bem como os descritores de cada um dos critérios de terceiro nível. São estes que servirão para avaliar cada uma das alternativas de decisão.

Tendo os critérios sido determinados e estruturados, isto é, descritos em uma perspectiva hierárquica, com um grau de detalhamento que torna possível a mensuração e comparação de seus diferentes níveis, pode-se, então, executar a próxima etapa do método AHP: a realização de julgamentos.

\subsection{Realização dos julgamentos}

O próximo passo no desenvolvimento do modelo consistiu em fazer a comparação pareada entre os critérios de mesmo nível, onde são avaliadas as

preferências relativas entre cada elemento de decisão. Para tanto, utilizou-se a Escala de Comparação de Pares do AHP, conforme apresentado no Quadro 1. Os valores desta escala são introduzidos em uma matriz. Para o Nível 2, a matriz toma a forma da Tabela 2.

Tabela 2 - Matriz de comparação pareada para o Nível 2

\begin{tabular}{ccccc}
\hline Critério & Orçamento & Entrega & Pagamento & Pós-venda \\
\hline Orçamento & 1,00 & 4,00 & 5,00 & 0,25 \\
Entrega & 0,25 & 1,00 & 3,00 & 0,17 \\
Pagamento & 0,20 & 0,33 & 1,00 & 0,14 \\
Pós-venda & 4,00 & 6,00 & 7,00 & 1,00 \\
\hline
\end{tabular}

Como se pode observar na Tabela 2, o critério "Pós-venda" é moderadamente a fortemente preferível em relação ao critério "Orçamento", e assim por diante. Para manter-se a consistência nos julgamentos, cada elemento $a_{i j}=k$ da matriz implica automaticamente que $a_{j i}=k^{-1}$. A diagonal principal é pontuada como igualmente preferível, tendo em vista que nela se situam as comparações de critérios idênticos.

A Tabela 3 apresenta as comparações pareadas para os subcritérios de Orçamento. 
Tabela 3 - Comparações pareadas para subcritérios de Orçamento

\begin{tabular}{ccccc}
\hline Critério & $\begin{array}{c}\text { Tempo de } \\
\text { resposta }\end{array}$ & $\begin{array}{c}\text { Validade da } \\
\text { proposta }\end{array}$ & $\begin{array}{c}\text { Prazo de } \\
\text { entrega }\end{array}$ & $\begin{array}{c}\text { Preço da } \\
\text { entrega }\end{array}$ \\
\hline Tempo de resposta & 1,00 & 6,00 & 0,33 & 0,33 \\
Validade da proposta & 0,17 & 1,00 & 0,14 & 0,25 \\
Prazo de entrega & 3,00 & 7,00 & 1,00 & 5,00 \\
Preço da entrega & 3,00 & 4,00 & 0,20 & 1,00 \\
\hline
\end{tabular}

A Tabela 4 apresenta as comparações pareadas para os subcritérios de Entrega, Pagamento e Pós-venda.

Tabela 4 - Comparações pareadas para subcritérios de Entrega, Pagamento e Pós-venda

\begin{tabular}{|c|c|c|}
\hline Critérios Entrega & $\begin{array}{c}\text { Correção } \\
\text { da NF }\end{array}$ & $\begin{array}{c}\text { Cumprimento } \\
\text { do prazo }\end{array}$ \\
\hline Correção da NF & 1,00 & 0,14 \\
\hline $\begin{array}{l}\text { Cumprimento do } \\
\text { prazo }\end{array}$ & 7,00 & 1,00 \\
\hline Critérios Pagamento & $\begin{array}{c}\text { Prazo de } \\
\text { pagamento }\end{array}$ & $\begin{array}{l}\text { Forma de } \\
\text { pagamento }\end{array}$ \\
\hline Prazo de pagamento & 1,00 & 3,00 \\
\hline Forma de pagamento & 0,33 & 1,00 \\
\hline Critérios Pós-venda & $\begin{array}{l}\text { Nível de } \\
\text { problemas }\end{array}$ & $\begin{array}{l}\text { Prontidão na } \\
\text { solução }\end{array}$ \\
\hline Nível de problemas & 1,00 & 4,00 \\
\hline Prontidão na solução & 0,25 & 1,00 \\
\hline
\end{tabular}

Em seguida, foi realizada a análise de consistência das matrizes de comparação, a fim de determinar se os julgamentos dos decisores eram coerentes. Foram calculados os quocientes de consistência (CR) das matrizes de acordo com a Eq. (1). A matriz da Tabela 2 possui $C R=0,086$, abaixo do limite recomendado, de forma que se conclui que possui julgamentos com bom nível de consistência. Todas as demais matrizes também tiveram os seus níveis de consistência abaixo do limite recomendado, sendo que no caso das matrizes de ordem $2, \lambda_{\max }=n$. Por conta disso, pôde-se proceder as demais etapas do desenvolvimento do modelo.

\subsection{Síntese das prioridades}

Nesta etapa, as matrizes são normalizadas para a obtenção das prioridades relativas de cada um dos critérios, de forma que a soma destas, em cada nível, seja 
um. A Tabela 5 apresenta a matriz de comparação para o Nível 2, em base percentual.

Tabela 5 - Matriz de comparação pareada para o Nível 2 em percentual

\begin{tabular}{cccccc}
\hline CRITÉRIO & Orçamento & Entrega & Pagamento & Pós-venda & $\begin{array}{c}\text { Prioridade } \\
\text { Relativa }\end{array}$ \\
\hline Orçamento & 0,1835 & 0,3529 & 0,3125 & 0,1603 & $\mathbf{2 5 , 2 3 \%}$ \\
Entrega & 0,0459 & 0,0882 & 0,1875 & 0,1069 & $\mathbf{1 0 , 7 1 \%}$ \\
Pagamento & 0,0367 & 0,0294 & 0,0625 & 0,0916 & $\mathbf{5 , 5 1 \%}$ \\
Pós-venda & 0,7339 & 0,5294 & 0,4375 & 0,6412 & $\mathbf{5 8 , 5 5 \%}$ \\
\hline Soma & 1,0000 & 1,0000 & 1,0000 & 1,0000 & $\mathbf{1 0 0 \%}$ \\
\hline
\end{tabular}

Fonte. Elaborada pelos autores

Neste caso, o elemento "Orçamento x Orçamento" é calculado da seguinte forma: $1 /(1,00+0,25+0,20+4,00)$, de acordo com a Tabela 2. Procede-se desta mesma forma para os demais elementos. A Prioridade Relativa nada mais é do que a média das pontuações de cada linha da matriz e representa o peso relativo de cada critério no respectivo nível.

Para os critérios de nível 3, as matrizes foram elaboradas utilizando-se os mesmo procedimentos, e terminada a etapa de comparação pareada e cálculo das prioridades relativas, elaborou-se a versão final da estrutura de decisão do AHP para a seleção de fornecedores no caso em análise, apresentada na Figura 2 com as prioridades relativas de cada critério.

Construiu-se, por fim, a função-objetivo, apresentada na Eq. (2), que agrega todos os critérios com suas respectivas prioridades relativas, sendo $V x$ o valor final de cada $x$ alternativa de decisão.

$V_{x}=\sum_{i \in \mathbb{N}} w_{i} \cdot v_{i}(x)$

onde:

$V_{x} \quad$ função-valor de cada $x$ alternativa de decisão

N conjunto de critérios de segundo nível

$w_{i} \quad$ peso de cada $i \in N$ critério de segundo nível

$\varpi_{i}(x) \quad$ função-valor de cada ieN critério de segundo nível, para cada $x$ alternativa de decisão.

Revista Produção Online, Florianópolis, SC, v.14, n. 1, p. 219-241, jan./mar. 2014. 
As funções-valor $v_{i}(x)$ de cada critério de segundo nível estão apresentadas nas Eqs. (3) a (6). Os valores de $w_{i}$ correspondem à última coluna da Tabela 4, em base unitária.

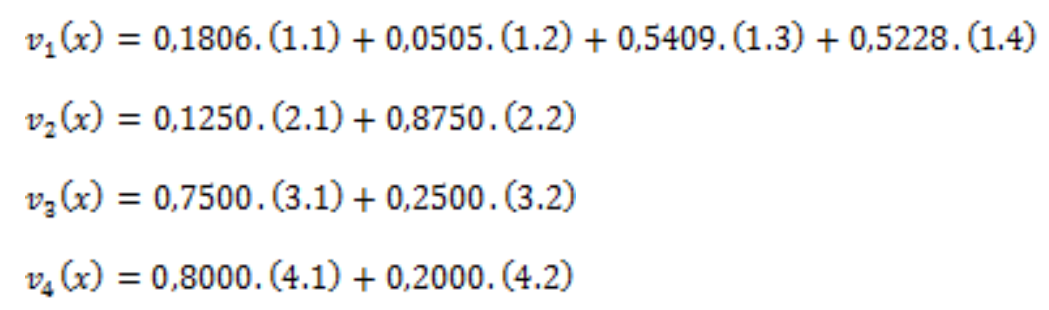

Tendo-se em mãos a síntese do modelo, conforme as Eqs. (2) a (6) e a estrutura de decisão da Figura 2, elaborou-se uma simulação do modelo com três fornecedores de equipamentos de informática ( $A, B$ e $C$ ), onde os mesmos forneceram um microcomputador. A Tabela 6 apresenta as notas de cada subcritério para os três fornecedores.

Tabela 6 - Pontuações para os três fornecedores

\begin{tabular}{cccc} 
& \multicolumn{3}{c}{ Fornecedor } \\
\cline { 2 - 4 } Critérios & A & B & C \\
\hline 1.1 & 0,0911 & 0,1823 & 0,1367 \\
1.2 & 0,0255 & 0,0255 & 0,0255 \\
1.3 & 0,5459 & 0,5459 & 0,6824 \\
1.4 & 0,1726 & 0,1726 & 0,0575 \\
2.1 & 0,0402 & 0,0402 & 0,0402 \\
2.2 & 0,1875 & 0,4686 & 0,3749 \\
3.1 & 0,1239 & 0,1239 & 0,0826 \\
3.2 & 0,0275 & 0,0413 & 0,0413 \\
4.1 & 2,3421 & 1,8737 & 1,4052 \\
4.2 & 0,3513 & 0,4684 & 0,3513 \\
\hline
\end{tabular}

Na Tabela 7 é apresentada a simulação completa para o fornecedor A. 
Tabela 7 - Simulação do fornecedor de informática A

\begin{tabular}{|c|c|c|c|}
\hline CRITÉRIO & NOTA & OBSERVAÇÃO & $\begin{array}{l}\text { NOTA } \\
\text { PONDERADA }\end{array}$ \\
\hline 1.1 & 2 & Demorou 4 dias para responder à solicitação de orçamento. & 0,0911 \\
\hline 1.2 & 2 & Apresentou uma proposta com validade de 15 dias. & 0,0255 \\
\hline 1.3 & 4 & $\begin{array}{l}\text { Deu um prazo de entrega de } 15 \text { dias, pois não tinha todos } \\
\text { os componentes em estoque, de forma que teve que } \\
\text { encomendá-los. }\end{array}$ & 0,5459 \\
\hline 1.4 & 3 & Não cobrou a entrega do produto. & 0,1726 \\
\hline 2.1 & 3 & A nota fiscal foi emitida corretamente. & 0,0402 \\
\hline 2.2 & 2 & $\begin{array}{l}\text { Entregou no vigésimo dia (atraso de } 33,33 \% \text { ), justificado } \\
\text { pelo atraso do seu fornecedor em entregar as peças } \\
\text { faltantes em seu estoque. }\end{array}$ & 0,1875 \\
\hline 3.1 & 3 & Emitiu a nota fiscal com vencimento em 7 dias. & 0,1239 \\
\hline 3.2 & 2 & $\begin{array}{l}\text { Não possui conta no Banco do Brasil, de forma que o } \\
\text { pagamento teve que ser feito com cheque. }\end{array}$ & 0,0275 \\
\hline 4.1 & 5 & $\begin{array}{l}\text { Alguns dos periféricos foram entregues na cor errada, o que } \\
\text { não impediu seu uso. }\end{array}$ & 2,3421 \\
\hline \multirow[t]{2}{*}{4.2} & 3 & A solução foi dada dentro de uma semana. & 0,3513 \\
\hline & & NOTA FINAL & 3,9075 \\
\hline
\end{tabular}

Na Tabela 8 têm-se os resultados da simulação completa para o fornecedor B.

Tabela 8 - Simulação do fornecedor de informática B

\begin{tabular}{cclc}
\hline & & \multicolumn{1}{c}{ OBSERVAÇÃO } & NOTA \\
CRITÉRIO & NOTA & PONDERADA \\
\hline 1.1 & 4 & O fornecedor respondeu à solicitação em poucas horas. & 0,1823 \\
1.2 & 2 & Apresentou uma proposta com validade de 15 dias. & 0,0255 \\
1.3 & 4 & Deu um prazo de entrega de uma semana. & 0,5459 \\
1.4 & 3 & Não cobrou a entrega. & 0,1726 \\
2.1 & 3 & A nota fiscal não apresentou problemas. & 0,0402 \\
2.2 & 5 & Entregou em 5 dias. & 0,4686 \\
3.1 & 3 & Emitiu uma cobrança com vencimento de 7 dias. & 0,1239 \\
3.2 & 3 & Emitiu um boleto de cobrança. & 0,0413 \\
4.1 & 4 & O produto não tinha instalado um software que havia sido & 1,8737 \\
4.2 & 4 & Solicitado. & 0,4684 \\
\hline \multicolumn{2}{c}{ NOTAcionou o problema no dia seguinte. } \\
\hline
\end{tabular}

Na Tabela 9 é apresentada a simulação completa para o fornecedor C. 
Tabela 9 - Simulação do fornecedor de informática C

\begin{tabular}{|c|c|c|c|}
\hline CRITÉRIO & NOTA & OBSERVAÇÃO & $\begin{array}{c}\text { NOTA } \\
\text { PONDERADA }\end{array}$ \\
\hline 1.1 & 3 & Respondeu à solicitação em 2 dias. & 0,1367 \\
\hline 1.2 & 2 & $\begin{array}{l}\text { Apresentou uma proposta com validade de } 15 \\
\text { dias. }\end{array}$ & 0,0255 \\
\hline 1.3 & 5 & Tinha o produto à pronta-entrega. & 0,6824 \\
\hline 1.4 & 1 & $\begin{array}{l}\text { Não entregou, solicitou que o produto fosse } \\
\text { coletado na loja. }\end{array}$ & 0,0575 \\
\hline 2.1 & 3 & A nota fiscal não tinha erros. & 0,0402 \\
\hline 2.2 & 4 & $\begin{array}{l}\text { O produto estava à disposição para retirada no } \\
\text { mesmo dia em que foi fechada a compra. }\end{array}$ & 0,3749 \\
\hline 3.1 & 2 & A compra foi negociada com pagamento à vista. & 0,0826 \\
\hline 3.2 & 3 & $\begin{array}{l}\text { O fornecedor tinha conta no Banco do Brasil. } \\
\text { O produto foi instalado e apresentou }\end{array}$ & 0,0413 \\
\hline 4.1 & 3 & $\begin{array}{l}\text { incompatibilidade com a rede, problema este } \\
\text { atribuído ao próprio produto, de forma que o seu } \\
\text { uso foi parcialmente limitado. }\end{array}$ & 1,4052 \\
\hline 4.2 & 3 & A solução foi dada dentro de uma semana. & 0,3513 \\
\hline
\end{tabular}

A Tabela 10 apresenta o ranking final do algoritmo AHP aplicado à decisão de seleção de fornecedor de material de informática, para o caso em estudo, em ordem decrescente de pontuação.

\begin{tabular}{cc}
\multicolumn{3}{c}{ Tabela 10 - Ranking final do AHP } \\
\hline FORNECEDOR & DESEMPENHO GLOBAL \\
\hline B & 3,9423 \\
A & 3,9075 \\
C & 3,1976 \\
\hline
\end{tabular}

Tendo em vista que se quer maximizar a função-objetivo, observa-se que o fornecedor B é o que deve ser selecionado, já que foi ele que alcançou a melhor pontuação. É este que tem maior potencial para fornecer produtos nas quantidades e especificações corretas, em um tempo curto e com o menor índice de transtornos aos projetos e à fundação, segundo os critérios levantados.

\section{CONSIDERAÇÕES FINAIS}

No presente artigo foi proposto um modelo de apoio à decisão de seleção de fornecedores, utilizando-se um método multicritério: o AHP. O modelo foi criado para atender a um tipo específico de organização: fundações de apoio a Instituições Federais de Ensino Superior, as quais se encontram inseridas num contexto que possui um conjunto de peculiaridades, conforme discutido, que justificam o seu 
desenvolvimento. Funcionários do setor de compras desta organização foram entrevistados, e ao todo dez critérios quantificáveis foram identificados.

Em um primeiro momento, foi estabelecida a estrutura hierárquica dos critérios para o problema, em um processo interativo com os decisores, o que permitiu a identificação e o ordenamento dos aspectos relevantes dentro da situação de decisão. Em seguida, procedeu-se a comparação pareada entre os critérios de mesmo nível, onde foram avaliadas as preferências relativas entre cada elemento da decisão. Também foi procedida a análise de consistência das matrizes de comparação.

$\mathrm{Na}$ etapa da síntese das prioridades, as matrizes foram manipuladas para a obtenção das prioridades relativas de cada um dos critérios, de forma que a soma destas fosse 1 nos níveis 2 e 3 da estrutura hierárquica. Foi feita a normalização dos valores para que todos tivessem a mesma ordem de grandeza.

Construiu-se a função-objetivo, que agregou todos os critérios com suas respectivas prioridades relativas do modelo. E com base nela e na estrutura hierárquica de decisão, elaborou-se uma simulação do modelo com três fornecedores para material de informática (A, B e C).

Com base na simulação, observou-se que os decisores estabeleceram um grande peso ao critério "Pós-venda" (58,55\%). Nesse sentido, pode-se interpretar que, para os atores da situação, esse critério possui impacto significativo na avaliação de um fornecedor de materiais de informática.

Os resultados foram apresentados para os decisores, os quais consideraram o instrumento válido como ferramenta de auxílio nas decisões de seleção de fornecedores em processos de compras.

O objetivo geral do trabalho, que se constituiu na construção de um modelo para auxiliar os gestores do setor de compras de uma fundação de apoio de determinada IFES na seleção de fornecedores para a modalidade de licitação de carta-convite, foi atingido com a elaboração da Equação (2) da função-objetivo e das Equações (3) (4) (5) e (6) das funções de valor.

Os objetivos específicos para a consecução desta pesquisa foram atingidos no decorrer do desenvolvimento do trabalho com a identificação dos critérios e subcritérios do modelo; o estabelecimento da hierarquia entre os critérios; a determinação das preferências relativas entre cada elemento de decisão; a análise 
de consistência das matrizes de comparação, a normalização das matrizes e elaboração da função-objetivo; e a avaliação das alternativas de decisão.

Dentre as limitações do trabalho estão a elevada demanda de tempo devido ao nível de intervenção do estudo de caso, a necessidade de alto grau de comprometimento dos decisores no processo de pesquisa e a impossibilidade de generalizações a partir do modelo multicritério construído para a fundação de apoio em questão.

Para futuras pesquisas, sugere-se a utilização do AHP para o desenvolvimento de um modelo de seleção de fornecedores em outras das 55 fundações de apoio que assessoram as Instituições Federais de Ensino Superior brasileiras. Em outra mão, seria interessante que o mesmo contexto fosse avaliado por outros atores que não os servidores do setor de compras; no caso específico, servidores da fundação que desenvolvem suas atividades na área de regulação e na área administrativa.

\section{AGRADECIMENTOS}

Os autores agradecem aos avaliadores anônimos pelas importantes e enriquecedoras contribuições ao trabalho.

\section{REFERÊNCIAS}

ALMEIDA, A. T. Multicriteria decision model for outsourcing contracts selection based on utility function and ELECTRE method. Computers and Operations Research, 34, p. 3569-3574, 2007.

BANDEIRA, D. L.; BECKER, J. L.; ROCHA, A. K. Sistemática multicritério para priorização de embarques marítimos. Revista de Administração Mackenzie, v. 11, n. 6, p. 107-130, 2010.

BRASIL. Lei no 8.666, de 21 de junho de 1993. Regulamenta o art. 37, inciso XXI, da Constituição Federal, institui normas para licitações e contratos da Administração Pública e dá outras providências. Diário Oficial da União, Brasília, DF, n. 116, 22 jun. 1993, seção I, p. 8269-8281.

CHEN, Y-J. Structured methodology for supplier selection and evaluation in a supply chain. Information Science, v. 181, p. 1651-1670, 2011.

COELHO, S. de C. T. Terceiro setor: Um estudo comparativo entre Brasil e Estados Unidos. 2. ed. São Paulo: Editora SENAC São Paulo, 2002.

Revista Produção Online, Florianópolis, SC, v.14, n. 1, p. 219-241, jan./mar. 2014. 
COLIN, E. C. Pesquisa operacional: 170 aplicações em estratégia, finanças, logística, produção, marketing e vendas. 1. ed. Rio de Janeiro: LTC, 2007.

DE BOER, L.; LABRO, E.; MORLACHI, P. A review of methods supporting supplier selection. European Journal of Purchasing \& Supply Management, v. 7, 75-89, 2001.

DIAS, M. F. P.; FENSTERSEIFER, J. E.; SELLITTO, M. A. Análise multicriterial em estratégia de operações: Estudo de caso com compradores de arroz de seis redes supermercadistas. Revista Produção Online, v. 11, n. 3, p. 707-734, 2011.

ENSSLIN, L.; ENSSLIN, S.; ROCHA, S.; MARAFON, A.; MEDAGLIA, T. Modelo multicritério de apoio à decisão construtivista no processo de avaliação de fornecedores. Revista Produção, v. 23, n. 2, p. 402-421, abril/jun. 2013.

FERREIRA, L., SANTI, E. Um modelo multicritério fuzzy-electre para o problema de seleção de fornecedores. In: Anais do SBPO - Simpósio Brasileiro de Pesquisa Operacional. Rio de Janeiro, 2012, p.262-273.

GIL, A. C. Como elaborar projetos de pesquisa. São Paulo: Atlas, 2002.

GOMES, F. S., COSTA, H., LOPES, E., P., CHAVES, M., C. Seleção de empresas para licitação em uma empresa do setor de petróleo. Pesquisa operacional para 0 desenvolvimento, v.5, n.2, p. 185-208, 2013.

$\mathrm{HO}, \mathrm{W}$. Integrated analytic hierarchy process and its applications: A literature review. European Journal of Operational Research, v. 186, n. 1, p. 211-228, 2008.

HO, W.; XU, X.; DEY, P. K. Multi-criteria decision making approaches for supplier evaluation and selection: A literature review. European Journal of Operational Research, v. 202, p. 16-24, 2010.

ISHIZAKA, A. Cluster and pivots for evaluating a large number of alternatives in AHP. Pesquisa Operacional, v. 32, n. 1, p. 87-101, 2012.

LIU, F. F.; HAI, H. L. The voting analytic hierarchy process method for selecting supplier. International Journal of Production Economics, v. 97, p. 308-317, 2005.

LONGARAY. A., A. A teoria da decisão revisitada: análise e perspectivas. Revista ANGRAD, 8, 137-152, 2007.

LONGARAY, A. A., ENSSLIN, L., MACKNESS, J. R. Uma proposta de integração da soft systems methodology à MCDA-C. Pesquisa Operacional para o

Desenvolvimento, v.5, p.331-372, 2013.

LONGARAY, A. A.; ENSSLIN, L. Uso da MCDA na identificação e mensuração da performance dos critérios para a certificação dos hospitais de ensino no âmbito do SUS. Revista Produção. Disponível em $<$ http://www.scielo.br/scielo.php?pid=S0103- 
$65132013005000021 \&$ script=sci arttext $>$. Acesso em 25 de setembro de 2013. http://dx.doi.org/10.1590/S0103-65132013005000021.

LONGARAY, A. A., CAPRARIO, G. N., ENSSLIN, L. Análise de decisão multicritério: um caso empregando o MACBETH. SINERGIA: Revista do Instituto de Ciências Econômicas, Administrativas e Contábeis da Universidade Federal do Rio Grande, 14(2), p.51-62, 2010.

MARCHEZETTI, A. L.; KAVISKI, E.; BRAGA, M. C. B. Aplicação do método AHP para a hierarquização das alternativas de tratamento de resíduos sólidos domiciliares. Ambiente Construído, v. 11, n. 2, p.173-187, 2011.

MIGUEL, P. A. C. (organizador). Metodologia de pesquisa em engenharia de produção e gestão de operações. Rio de Janeiro: Elsevier, 2010.

PAULA, J. O. de; MELLO, C. H. P. Seleção de um modelo de referência de PDP para uma empresa de autopeças através de um método de auxílio à decisão por múltiplos critérios. Revista Produção, v. 23, n. 1, p. 144-156, jan/mar. 2013.

RAMOS FILHO, J. A.; ATAMANCZUK, M. J.; MARÇAL, R. F. M. Seleção de técnicas de manutenção para processo de armazenagem pelo método de análise hierárquica. Revista Produção Online, v. 10, n. 1, p. 142-166, 2010.

RIBEIRO, L. de S.; PASSOS, A. C.; TEIXEIRA, M. G. Seleção de tecnologias de comunicação no exército brasileiro utilizando os métodos multicritério de análise hierárquica, TODIM e software Sapiens. Produção, v. 22, n. 1, p. 132-141, 2012.

SAATY, T. How to make a decision: The analytic hierarchy process. European Journal of Operational Research, v. 48, 9-26, 1990.

SAATY, T. Método de análise hierárquica. São Paulo: Makron Books, 1991.

SALOMON, V. A. P. Auxílio à decisão para adoção de políticas de compras.

Produto \& Produção, v. 6, n. 1, p. 01-08, 2002.

SALOMON, V. A. P. Desempenho da modelagem do auxílio à decisão por múltiplos critérios na análise do planejamento e controle da produção. 2004. Teste (Doutorado em Engenharia) - Escola Politécnica, Universidade de São Paulo, São Paulo. 2004.

SALOMON, V. A. P, MARINS, F., DUDUCH, M. Tomada de decisões múltiplas aplicada à seleção de fornecedores de equipamentos de uma linha de montagem em uma fábrica de autopeças. Pesquisa Operacional para o Desenvolvimento, v. 1, n. 3, p. 208-217, 2009.

SILVA, B.; FINARDI, C.; FORNECK, M.; SELLITTO, M. A. Análise comparativa e avaliação de prioridades de competição em três cadeias de suprimentos do setor petroquímico. Revista Produção, v. 22, n. 2, p. 225-236, 2012. 
SUBRAMANIAN, N.; RAMANATHAN, R. A review of applications of Analytic Hierarchy Process in operations management. International Journal of Production Economics, v. 138, p. 215-241, 2012.

WOLLMANN, D.; STEINER, M. T. A.; VIEIRA, G. E.; STEINER, P. A. Avaliação de operadoras de saúde por usuários pelo método Analytic Hierarchy Process. Revista Saúde Pública, v. 46, n. 5, p. 777-783, 2012.

YIN, R. K. Estudo de caso: Planejamento e métodos. 3. ed. Porto Alegre: Bookman, 2005.

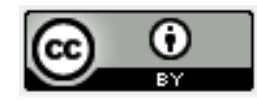

Artigo recebido em 05/05/2013 e aceito para publicação em 09/09/2013.

DOI: http://dx.doi.org/10.14488/1676-1901.v14.i1.1586 